\title{
PENILAIAN ASPEK ERGONOMI TERHADAP BURUH ANGKUT ARANG
}

\author{
Marta Hayu Raras Sita Rukmika Sari \\ Program Studi Teknik Industri, Politeknik META Industri Cikarang \\ marta@politeknikmeta.ac.id
}

\begin{abstract}
Charcoal hauling is work that has a high risk of injury, especially if the work is carried out repeatedly for a long period of time. This research be able to assess whether this work is still in the safe category just because it only takes about 2 hours everyday.

The review was carried out 2 times. The initial review uses the Nordic Body Map Qustionare too find out complaints experienced by workers. Further review is carried out by assessing body posture using REBA and OWAS, and also assessing the appropriateness of the burden of the manual material handling process using a snook table.

The assessment results show that the body posture in the work of charcoal hauling has risks and needs immediate improvement. In addition, the burden carried by workers is also classified as exceeding the maximum recommended load. The solution of this problem is to use goods hand trolley that useful to lighten the movement and also improve worker posture because they do not need to hold the burden on the head or neck.
\end{abstract}

Keywords : repetition, body posture, Manual Material Handling, REBA, OWAS, Snook Table

\section{ABSTRAK}

Pekerjaan yang dilakukan buruh angkut arang merupakan pekerjaan yang memiliki resiko besar terhadap cedera, terlebih jika pekerjaan dilakukan secara berulang (repetition) dalam jangka waktu yang lama. Oleh karena itu penelitian ini diangkat untuk dapat menilai apakah pekerjaan ini masih dalam kategori aman karena hanya berlangsung kurang lebih 2 jam setiap harinya.

Tinjauan dilakukan sebanyak 2 kali. Tinjauan awal menggunakan Nordic Body Map Questionare untuk mengetahui keluhan yang dialami pekerja. Tinjauan lanjutan dilakukan dengan menilai postur tubuh menggunakan REBA dan OWAS, serta menilai kelayakan beban dari proses manual material handling dengan menggunakan snook table.

Hasil penilaian menunjukkan bahwa postur tubuh dalam pekerjaan buruh angkut arang memiliki resiko dan perlu segera dilakukan perbaikan. Selain itu, beban yang diangkut oleh pekerja juga tergolong melebihi batas maksimum beban yang disarankan. Dari situ muncul solusi untuk mengadakan hand trolley barang. Selain dapat meringankan dalam proses perpindahan, hand trolley barang juga dapat memperbaiki postur pekerja karena tidak perlu menahan beban di kepala maupun leher.

Kata Kunci : repetition, postur tubuh, Manual Material Handling, REBA, OWAS, Snook Table

\section{PENDAHULUAN}

Penelitian dilakukan di Pasar Demangan yang berada di Jalan Gejayan, Sleman, Yogyakarta. Di Pasar Demangan ini terdapat seorang buruh angkut yang memiliki pekerjaan mengangkut arang dari mobil angkut sampai ke dalam pasar dengan jarak 75 meter. Arang yang dipindahkan sebanyak 50 karung dengan berat masing-masing karung sebesar $25 \mathrm{~kg}$. Pekerjaan ini dilakukan setiap harinya di jam 16.00 WIB atau 4 sore selama durasi waktu sekitar 2 jam. Elemen-elemen pekerjaan yang dilakukan dalam aktivitas mengangkut arang ini antara lain adalah mengangkat arang dari mobil angkut ke kepala, membawa arang ke dalam pasar, meletakkan arang ke 
tempat penyimpanan. Menurut Sari, dkk (2015) proses Lifting (mengangkat), Carrying (membawa), Lowering (menurunkan) merupakan bagian dari Manual Material Handling, sehingga selain berkaitan dengan postur tubuh, pekerjaan buruh angkut arang berkaitan erat dengan proses material handling.

Analisis ergonomi terhadap pekerja angkut arang di Pasar Demangan ini memiliki manfaat untuk mengetahui apakah pekerjaan ini masih dalam kategori aman ditinjau dari keluhan yang dialami pekerja serta penilaian aspek ergonomi yang dilakukan. Setelah mengetahui permasalahan yang ada, penulis dapat membuat solusi dan usulan untuk memperbaiki sistem kerja yang ada agar dapat membuat pekerja lebih nyaman dan terhindar dari penyakit akibat kerja. Penelitian ini untuk memastikan bahwa pekerja dapat bekerja secara ergonomis dimana tujuan dari ergonomi sendiri adalah agar manusia dapat bekerja dengan efektif, aman, sehat, nyaman dan efisien (Sutalaksana, dkk., 2006).

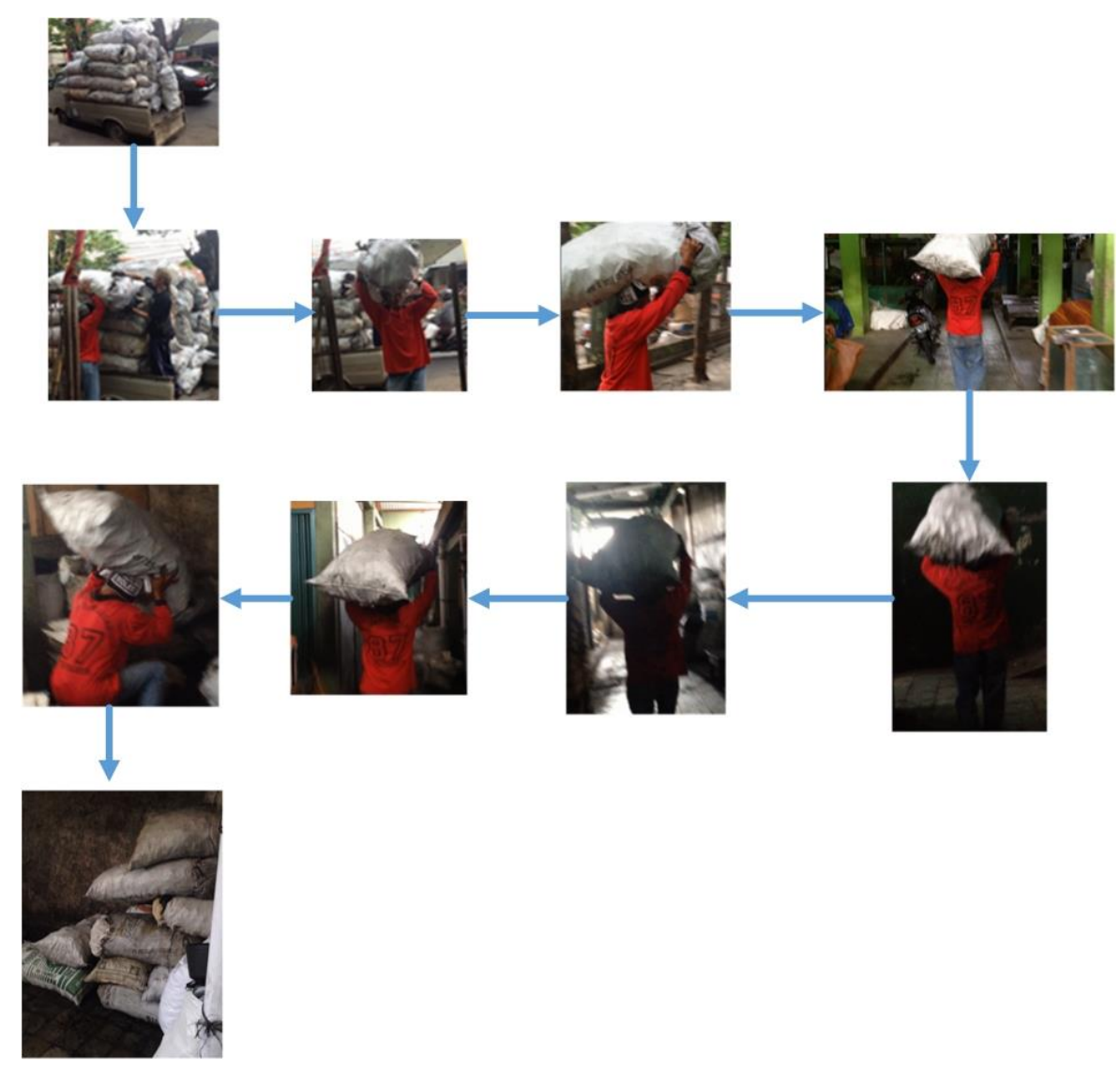

Gambar 1. Aktivitas Pengangkutan Arang dari Mobil Angkut ke Tempat Penyimpanan

\section{METODE PENELITIAN}

Obyek penelitian ini adalah buruh angkut arang yang berada di Pasar Demangan Yogyakarta. Obyek penelitian tersebut akan dianalisis menggunakan beberapa penilaian aspek ergonomi. Tinjauan terhadap obyek penelitian dilakukan 2 kali yaitu tinjauan awal dan tinjauan lanjutan. Tinjauan awal menggunakan Nordic Body Map Questionare yang dgunakan untuk mengetahui keluhan rasa sakit yang dialami pekerja akibat aktivitas yang dilakukan setiap harinya. Tinjauan lanjutan adalah penilaian yang mendukung penelitian untuk mengetahui kondisi awal obyek penelitian tersebut, diantaranya adalah: 
1. Penilaian untuk postur kerja menggunakan REBA dan OWAS

2. Penilaian Material handling menggunakan snook table untuk kegiatan lifting, carrying, dan lowering (Sari., dkk.,2015)

\section{HASIL DAN PEMBAHASAN}

Tinjauan awal penelitian ini yaitu penggunaan Nordic Body Map Questionare untuk mengetahui keluhan rasa sakit pekerja. Berikut hasil kuesioner yang didapatkan.

\section{NORDIC BODY MAP QUESTIONARE}

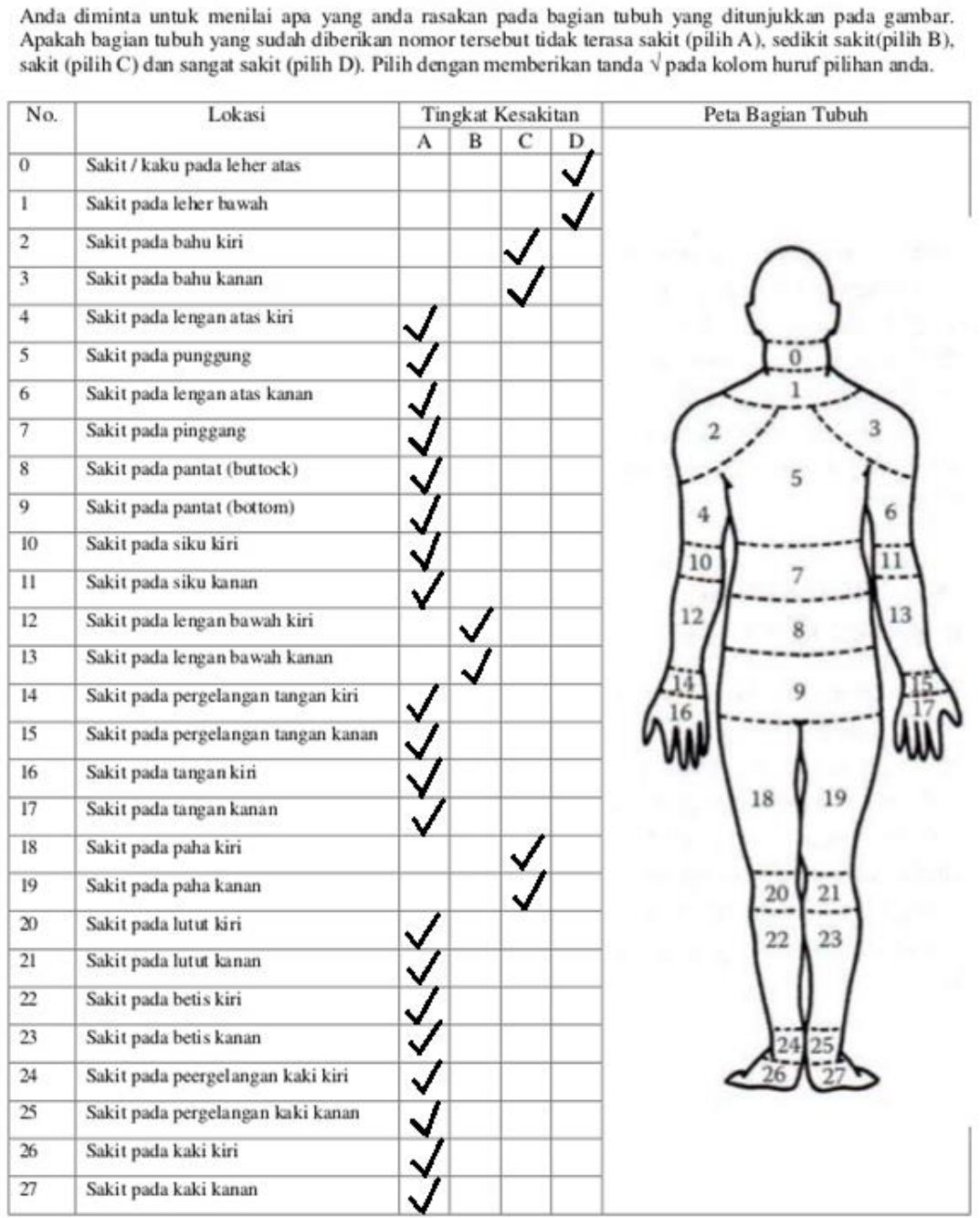

Gambar 2. Hasil Nordic Body Map Questionare

Dari hasil kuesioner tersebut didapatkan kesimpulan bahwa keluhan sakit yang dirasakan pekerja akibat pekerjaan yang ia lakukan paling terasa di bagian leher atas dan leher bawah. Pekerja menjelaskan bahwa rasa sakit di bagian leher tersebut dirasakan setiap harinya, kemudian untuk bagian bahu dan paha hanya terasa pegal saja namun sangat sering terjadi, sedangkan untuk bagian lengan hanya kadang-kadang saja terasa pegal.

Setelah mengetahui keluhan yang dirasakan oleh pekerja maka dilakukan tinjauan lanjutan, antara lain: 


\section{a. Penilaian Postur Kerja}

Penilaian yang digunakan untuk menganalisis postur kerja dari pekerja angkut arang ini sebenarnya dapat dilakukan dengan menggunakan OWAS. Namun OWAS memiliki keterbatasan yaitu tidak melibatkan penilaian pada leher, sedangkan aktivitas pengangkutan arang ini erat kaitannya dengan resiko cedera pada leher. Oleh karena itu penulis melakukan analisis dengan cara membagi pekerjaan menjadi beberapa elemen dan menganalisis satu per satu postur kerja dari masing-masing elemen kerja. Berikut adalah penilaian untuk masingmasing elemen kerja:

\subsubsection{Penilaian postur kerja untuk elemen pekerjaan mengangkat arang dari mobil angkut ke kepala}

Untuk elemen pekerjaan mengangkat arang dari mobil angkut ke kepala, penulis menggunakan alat penilaian berupa REBA. Hal ini dikarenakan dengan menggunakan REBA maka penilaian postur kerja untuk elemen ini dapat dilakukan secara mendetail mulai dari leher, punggung, lengan atas, lengan bawah, dan kaki.
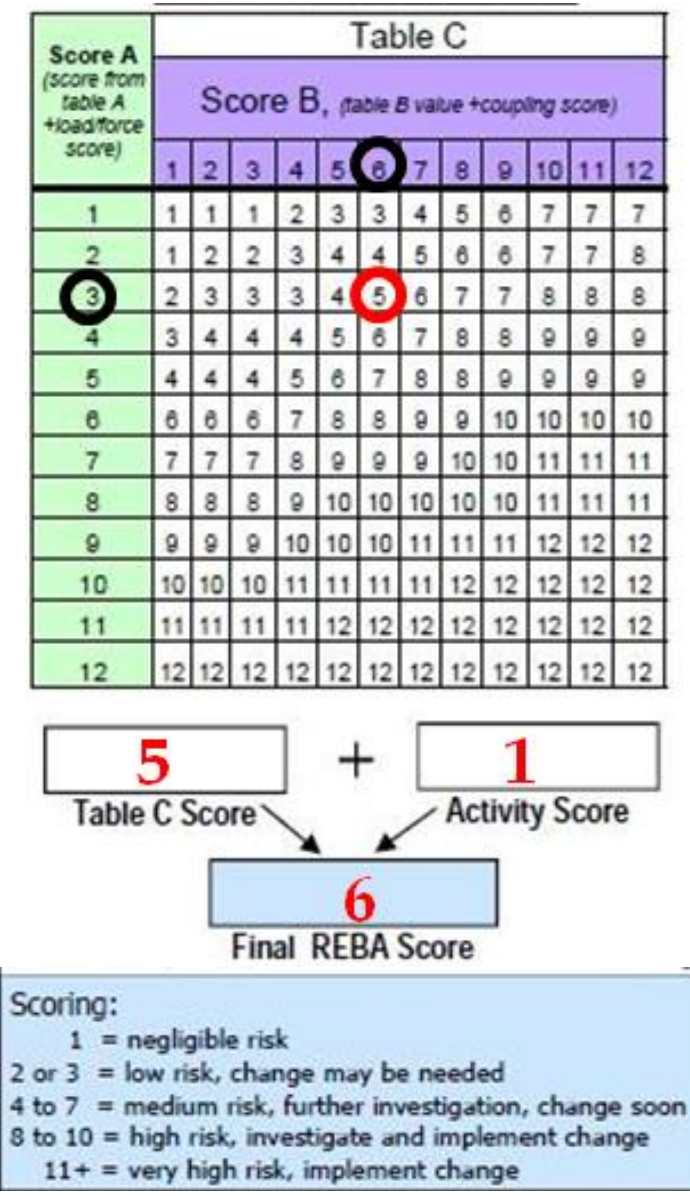

Gambar 3. Final REBA Score untuk Elemen Kerja Mengangkat Arang

Hasil analisis menggunakan REBA ini adalah resiko medium dan sesegera mungkin dilakukan perbaikan untuk elemen pekerjaan mengangkat arang dari mobil angkut ke kepala 


\subsubsection{Penilaian postur kerja untuk elemen pekerjaan membawa arang ke dalam pasar}

Untuk elemen pekerjaan membawa arang ke dalam pasar, penulis menggunakan alat penilaian berupa OWAS. Hal ini dikarenakan pekerjaan dilakukan dengan mobilitas yang tinggi (tidak statis). Selain itu, ditinjau dari faktor-faktor penilaiannya seperti punggung, lengan, kaki, dan beban kerja yang di gambarkan pada metode OWAS ini, sudah mewakili postur tubuh pada saat membawa arang ke dalam pasar.

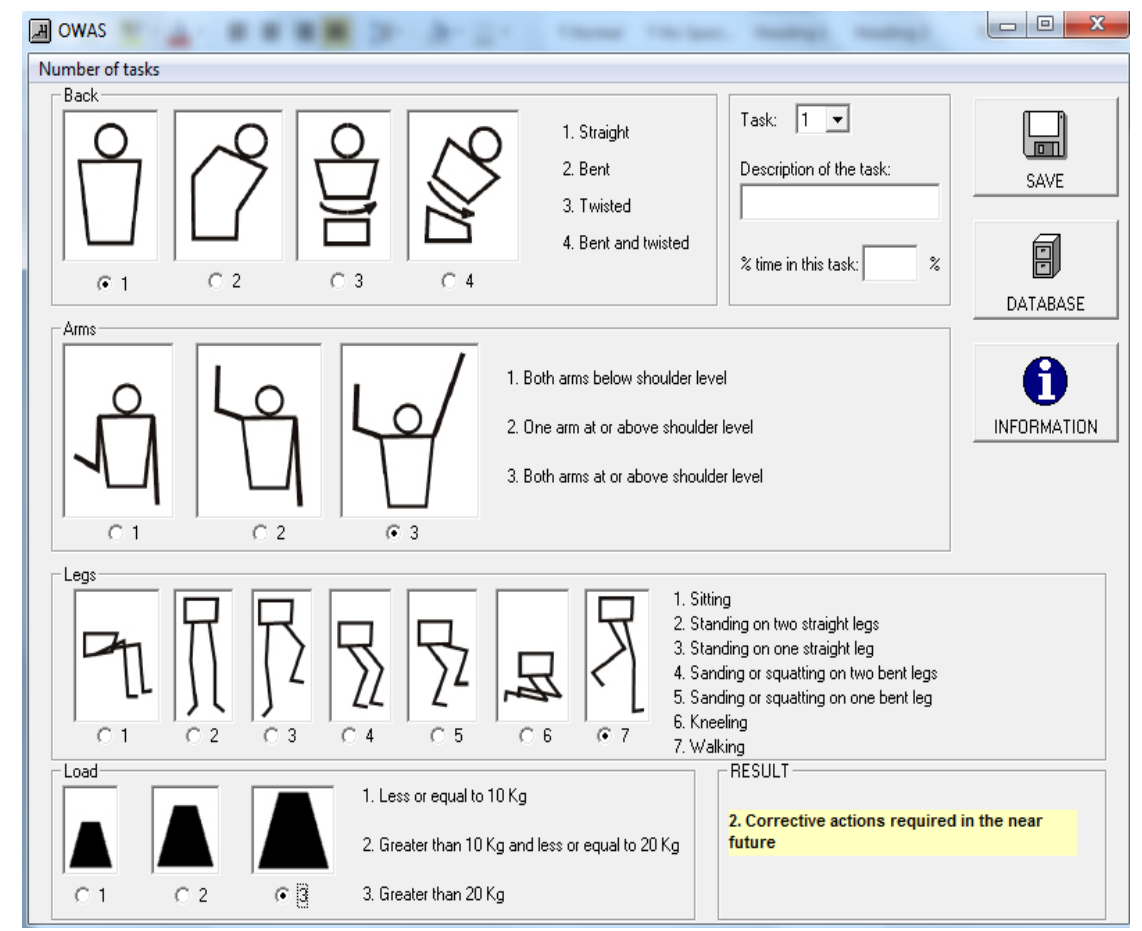

Gambar 4. OWAS Score untuk Elemen Pekerjaan Membawa Arang

Sama seperti yang ada di OWAS Work Sheet, skor yang didapatkan adalah 2, yaitu perlu adanya perbaikan postur tubuh untuk elemen pekerjaan membawa arang ke dalam pasar. 
3.1.3 Penilaian postur kerja untuk elemen pekerjaan meletakkan arang ke tempat penyimpanan

Sama seperti elemen mengangkat arang dari mobil angkut ke kepala, elemen meletakkan arang ke tempat penyimpanan ini menggunakan alat penilaian berupa REBA.

\begin{tabular}{|c|c|c|c|c|c|c|c|c|c|c|c|c|}
\hline \multirow{3}{*}{$\begin{array}{l}\text { Score A } \\
\text { (score from } \\
\text { table A } \\
\text { +loadrorce } \\
\text { score) }\end{array}$} & \multicolumn{12}{|c|}{ Table C } \\
\hline & \multicolumn{12}{|c|}{ Score B, fable B vale tcoupling scons) } \\
\hline & 1 & 2 & 3 & 4 & 5 & b. & 7 & 8 & 9 & 10 & 11 & 12 \\
\hline 1 & 1 & 1 & 1 & 2 & 3 & 3 & 4 & 5 & 6 & 7 & 7 & 7 \\
\hline 2 & 1 & 2 & 2 & 3 & 4 & 4 & 5 & 6 & 6 & 7 & 7 & 8 \\
\hline 3 & 2 & 3 & 3 & 3 & 4 & 5 & 6 & 7 & 7 & 8 & 8 & 8 \\
\hline 4 & 3 & 4 & 4 & 4 & 5 & 6 & 7 & 8 & 8 & 9 & $\theta$ & 8 \\
\hline 5 & 4 & 4 & 4 & 5 & 6 & 7 & 8 & 8 & $\theta$ & 8 & $\theta$ & $\theta$ \\
\hline 8 & 6 & 6 & 6 & 7 & 8 & 8 & 8 & 8 & 10 & 10 & 10 & 10 \\
\hline 8 & 7 & 7 & 7 & 8 & 8 & (e) & 2 & 10 & 10 & 11 & 11 & 11 \\
\hline 8 & 8 & 8 & 8 & 9 & 10 & 10 & 10 & 10 & 10 & 11 & 11 & 11 \\
\hline 9 & 9 & 9 & 9 & 10 & 10 & 10 & 11 & 11 & 11 & 12 & 12 & 12 \\
\hline 10 & 10 & 10 & 10 & 11 & 11 & 11 & 11 & 12 & 12 & 12 & 12 & 12 \\
\hline 11 & 11 & 11 & 11 & 11 & 12 & 12 & 12 & 12 & 12 & 12 & 12 & 12 \\
\hline 12 & 12 & 12 & 12 & 12 & 12 & 12 & 12 & 12 & 12 & 12 & 12 & 12 \\
\hline
\end{tabular}

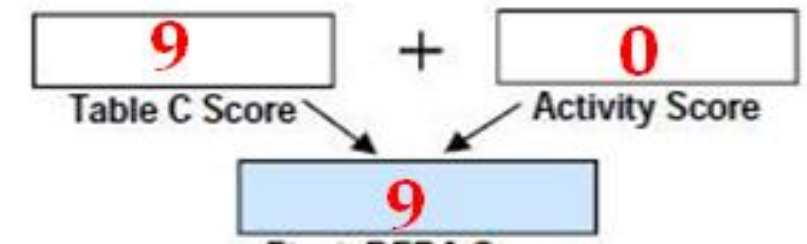

\section{Final REBA Score}

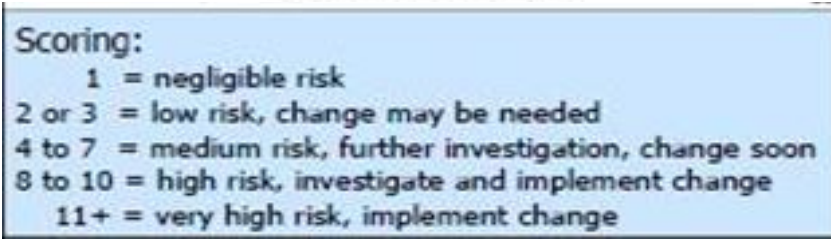

Gambar 5. Final REBA Score untuk Elemen Kerja Meletakkan Arang

Hasil analisis menggunakan REBA ini adalah resiko tinggi dan sesegera mungkin dilakukan perbaikan serta implementasi untuk elemen pekerjaan meletakkan arang ke tempat penyimpanan. 


\section{b. Penilaian Material Handling}

\subsubsection{Lifting}

Diketahui jarak dari karung arang ke tubuh pekerja (width) adalah $30 \mathrm{~cm}$, dan jarak vertikalnya (distance) adalah $100 \mathrm{~cm}$. Durasi untuk satu kali lifting adalah 2 menit dengan persen populasi 50\% dikarenakan pekerja angkutnya hanya 1 sedangkan jumlah total pekerjanya ada 2. Berdasarkan penilaian snook table pada Gambar 6 dan juga data-data yang tersedia, maka beban maksimum yang dapat diterima untuk mengangkat keatas (lifting) adalah sebesar $25 \mathrm{~kg}$.

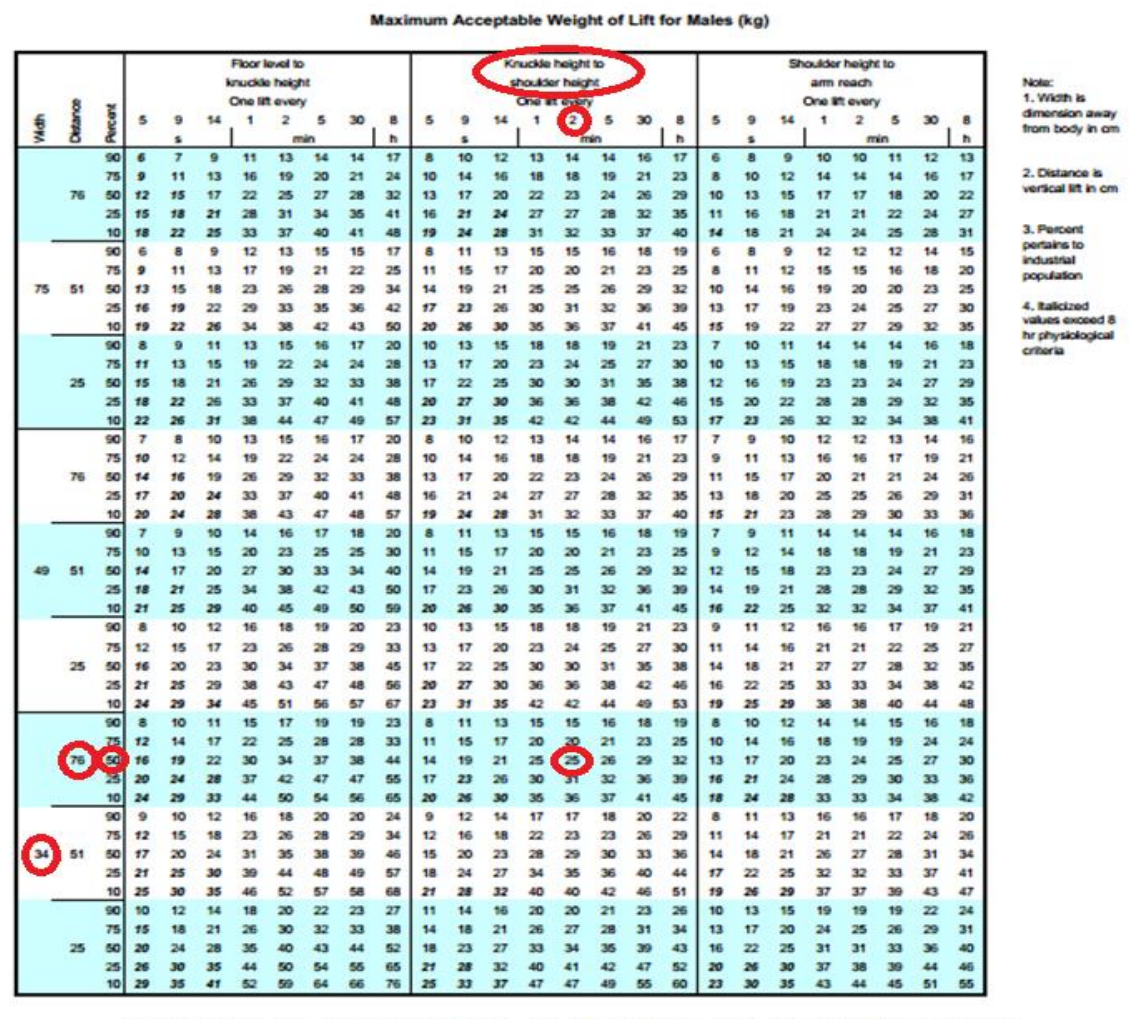

Gambar 6. Penilaian Lifting dengan Menggunakan Snook Table

\subsubsection{Carrying}

Diketahui jarak vertikal dari lantai ke tangan $160 \mathrm{~cm}$ (sesuai tinggi pekerja), jarak perpindahannya 75 meter, durasi pengangkatan 1 menit. Persen populasi menggunakan 90\% karena hanya ada 1 pekerja pengangkut arang ke dalam pasar. Berdasarkan penilaian snook table pada Gambar 7 dan data-data yang tersedia maka beban maksimum yang dapat diterima untuk membawa (carrying) adalah sebesar $13 \mathrm{~kg}$.

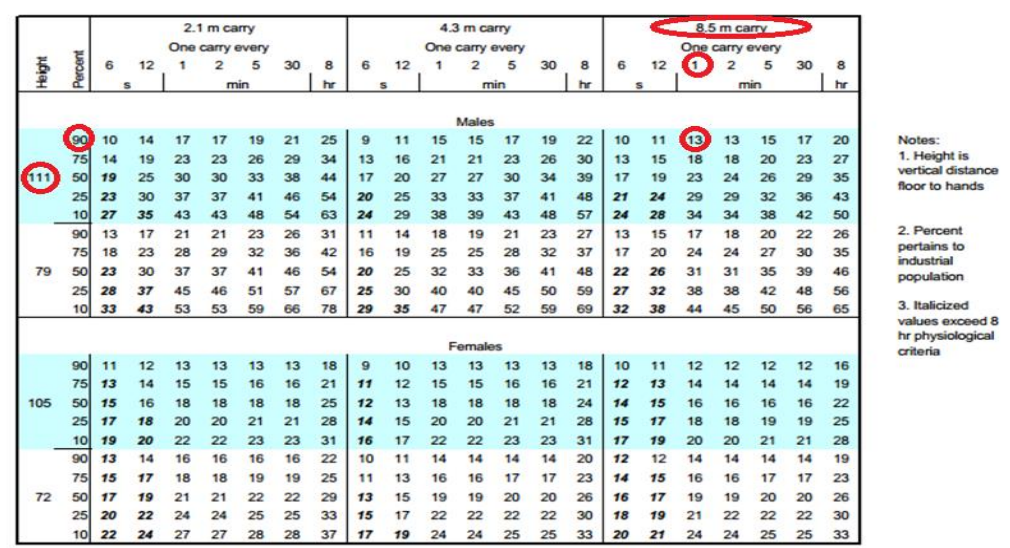

Gambar 7. Penilaian Carrying dengan Menggunakan Snook Table 


\subsubsection{Lowering}

Diketahui jarak dari karung arang ke tubuh pekerja (width) adalah $30 \mathrm{~cm}$, dan jarak vertikalnya (distance) adalah $160 \mathrm{~cm}$ sesuai tinggi pekerja, karena tempat untuk meletakkan arang adalah lantai. Durasi untuk satu kali lowering adalah 2 menit. Untuk persen populasinya menggunakan $90 \%$ karena yang bekerja menurunkan arang hanya 1 pekerja. Berdasarkan penilaian snook table pada Gambar 8 dan data-data yang tersedia maka beban maksimum yang dapat diterima untuk menurunkan (lowering) adalah sebesar $17 \mathrm{~kg}$.

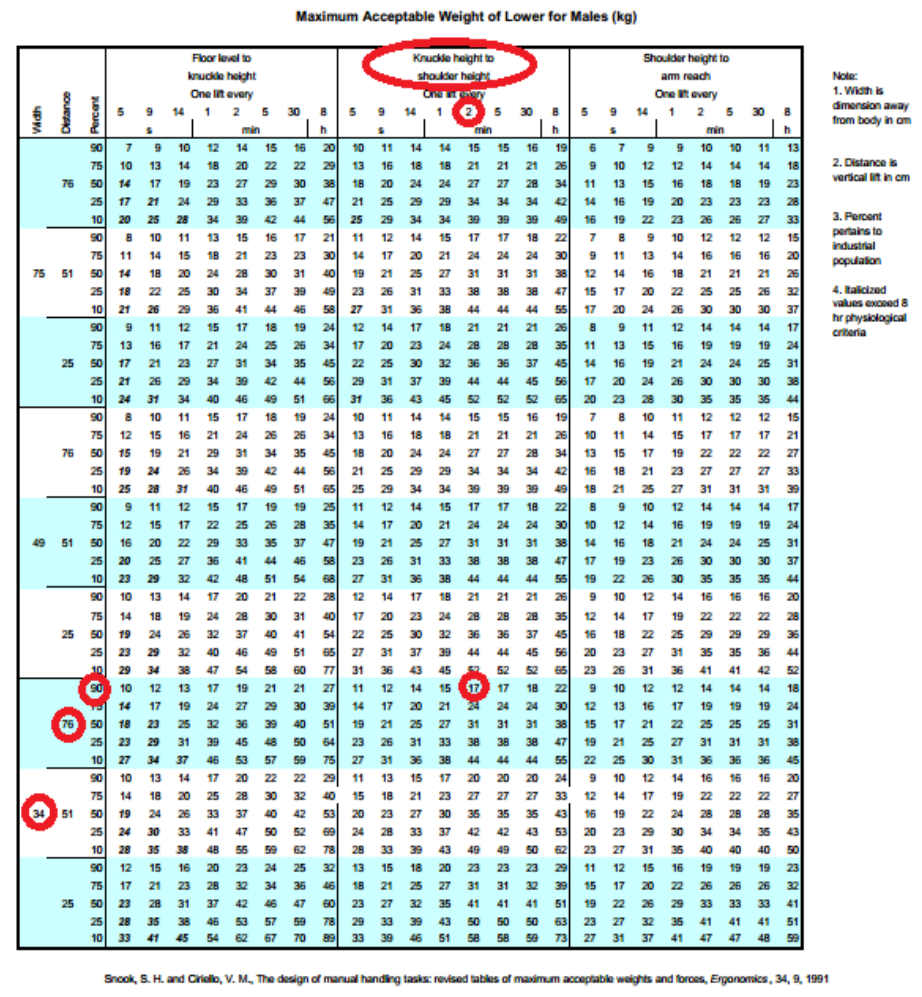

Gambar 8. Penilaian Lowering dengan Menggunakan Snook Table

Tabel 1 berikut adalah rekapan hasil penilaian postur dan juga material handling terhadap aktivitas buruh angkut arang yang menjadi obyek penelitian ini.

Tabel 1. Rekap Penilaian Postur dan Material Handling Buruh Angkut Arang

\begin{tabular}{|l|l|l|}
\hline Elemen Pekerjaan & Postur & Material Handling \\
\hline Mengangkat Arang & $\begin{array}{l}\text { Resiko medium, perlu } \\
\text { perbaikan }\end{array}$ & $\begin{array}{l}\text { Beban arang tidak melebihi beban } \\
\text { yang disarankan }\end{array}$ \\
\hline Membawa Arang & Perlu perbaikan & $\begin{array}{l}\text { Beban arang melebihi beban yang } \\
\text { disarankan }\end{array}$ \\
\hline Meletakkan Arang & Resiko tinggi, perlu perbaikan & $\begin{array}{l}\text { Beban arang melebihi beban yang } \\
\text { disarankan }\end{array}$ \\
\hline
\end{tabular}

Dari penilaian yang telah dilakukan dapat disimpulkan bahwa pekerjaan buruh angkut arang sangat beresiko karena dapat menimbulkan cedera jika dilakukan dalam jangka waktu yang lama. Oleh karena itu perlu adanya sebuah solusi untuk mencegah terjadinya cedera pada pekerja tersebut. Jika dilihat dari penilaian material handling untuk elemen mengangkat arang 
dengan beban $25 \mathrm{~kg}$ masih tergolong beban yang diperbolehkan untuk diangkat secara berulang/ repetition. Namun berbeda dengan 2 elemen pekerjaan lainnya yaitu membawa dan juga meletakkan arang, dimana $25 \mathrm{~kg}$ sudah melebihi beban yang disarankan. Selain itu, penilaian postur tubuh juga menunjukkan bahwa postur tubuh buruh angkut dalam melakukan pekerjaan sangat beresiko dan membutuhkan perbaikan segera. Ditinjau dari hal tersebut, maka disarankan untuk mengadakan hand trolley barang untuk membantu buruh angkut ini dalam memindahkan arang dari mobil angkut menuju tempat penyimpanan. Selain dapat membantu dari segi material handling, postur tubuh pun menjadi lebih baik karena tidak perlu menahan beban yang berat di kepala maupun leher.

\section{KESIMPULAN}

Penilaian aspek ergonomi terhadap buruh angkut arang ini dilaksanakan dengan menggunakan 2 tahap, yaitu tahap awal untuk mengetahui keluhan yang dirasakan oleh pekerja dengan menggunakan Nordic Body Map Questionare dan tahap lanjutan yang digunakan untuk menilai kondisi awal fisik pekerja dalam melakukan aktivitas mengangkut arang. Dari kedua tahapan didapatkan bahwa pekerjaan tersebut memiliki resiko cedera terlebih jika dilakukan dalam jangka waktu yang lama. Hal tersebut dapat diketahui dari hasil penilaian REBA dan OWAS yang menunjukkan bahwa aktivitas mengangkut arang beresiko dan perlu segera dilakukan perbaikan, selain itu nilai snook table juga menunjukkan bahwa beban yang diangkut melebihi beban yang disarankan sehingga beresiko pula menimbulkan cedera untuk aktivitas repetition seperti ini.

Oleh karena itu, diperlukan solusi untuk dapat menurunkan resiko kerja buruh angkut tersebut, yaitu dengan cara mengadakan bantuan alat dalam membantu proses material handling pengangkutan. Hand trolley barang dapat menjadi solusi untuk menurunkan resiko cedera pada buruh angkut arang karena dapat membantu dalam proses material handling dari mobil angkut menuju tempat penyimpanan, serta memperbaiki postur kerja karena tidak perlu menahan beban pada kepala maupun leher.

\section{DAFTAR PUSTAKA}

Ciriello, V., \& Snook, S. (n.d.). Table for Evaluating Lifting, Lowering, Pushing, and Carrying Task. Amerika Serikat: Liberty Mutual.

Sari, Marta Hayu Raras Sita Rukmika., Dewi, Luciana Triani., Ariyono, V.(2015). Analisis Ergonomi Aktivitas Pemindahan Bahan Akibat Pengaturan Ulang Tata Letak Stasiun Kerja. Proceeding Seminar Nasional dan Kongres PEI 2015. L12-L16.

Sutalaksana, I., Anggawisastra, R., \& Tjakraatmadja, J. (2006). Teknik Perancangan Sistem Kerja. Bandung: ITB 